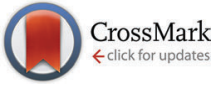

Cite this: Phys. Chem. Chem. Phys., 2015, 17, 12340

Received 13th November 2014, Accepted 8th April 2015

DOI: $10.1039 / c 4 c p 05273 k$

www.rsc.org/pccp

\section{The influence of the textural properties of activated carbons on acetaminophen adsorption at different temperatures $\dagger$}

\author{
Margarida Galhetas, ${ }^{a b}$ Marta A. Andrade, ${ }^{a}$ Ana S. Mestre, ${ }^{a}$ Ekoé Kangni-foli, ${ }^{a}$ \\ Maria J. Villa de Brito, ${ }^{c}$ Moisés L. Pinto, ${ }^{* d}$ Helena Lopes $^{b}$ and Ana P. Carvalho*a
}

\begin{abstract}
The influence of temperature $\left(20-40^{\circ} \mathrm{C}\right)$ on the acetaminophen adsorption onto activated carbons with different textures was studied. Different temperature dependences, not explained by kinetic effects, were observed for carbons with different micropore size distribution patterns: adsorption capacity increased for pine gasification residues ( $\mathrm{Pi}-\mathrm{fa}$ ) derived carbons and decreased for sisal based materials. No significant variation was seen for carbon CP. The species identified by ${ }^{1} \mathrm{H}$ NMR spectroscopy on the back-extraction solution proved that during the adsorption process exist the conditions required to promote the formation of acetaminophen oligomers which have constrained access to the narrow microporosity. The rotation energy of the dihedral angle between monomers (estimated by electronic DFT methods) showed that conformations in the planar form are less stable than the non-planar conformation (energy barrier of 70 and $23 \mathrm{~kJ} \mathrm{~mol}^{-1}$ ), but have critical dimensions similar to the monomer and can access most of the micropore volume. The enthalpy change of the overall process showed that the energy gain of the system (endothermic) for Pi-fa samples $\left(\approx 40 \mathrm{~kJ} \mathrm{~mol}{ }^{-1}\right.$ ) was enough to allow a change in the dimer, or even a larger oligomer, conformation to the planar form. This will permit adsorption in the narrow micropores, thus explaining the uptake increase with temperature. Non-continuous micropore size distributions centered at pore widths close to the critical dimensions of the planar form seem to be crucial for a positive evolution of the adsorption capacity with temperature.
\end{abstract}

\section{Introduction}

Activated carbons have been successfully applied as adsorbents of a variety of organic pollutants from aqueous solution. ${ }^{1-3}$ However, despite a great number of studies being focused on the performance of the materials, ${ }^{2-6}$ only in a few cases has some insight into the mechanism of the adsorption process been reported. ${ }^{7,8}$

The mechanism of the adsorption from solution is not an easy issue to address, due to the competition of the organic compounds and water for the adsorption sites, which depends

\footnotetext{
${ }^{a}$ Centro de Quimica e Bioquimica, Faculdade de Ciências, Universidade de Lisboa, 1749-016 Lisboa, Portugal. E-mail: ana.carvalho@fc.ul.pt; Fax: +351 217500888; Tel: +351217500897

${ }^{b}$ LNEG, Estrada do Paço do Lumiar 22, 1749-032 Lisboa, Portugal

${ }^{c}$ Centro de Química Estrutural (CQE), Departamento de Quimica e Bioquimica, Faculdade de Ciências, Universidade de Lisboa, 1749-016, Lisboa, Portugal

${ }^{d}$ CERENA, Departamento de Engenharia Quimica, Instituto Superior Técnico, Universidade de Lisboa, Av. Rovisco Pais, 1, 1049-001 Lisboa, Portugal. E-mail: moises.pinto@ua.pt; Fax: +351 234401470; Tel: +351 234401419

$\dagger$ Electronic supplementary information (ESI) available: NMR results are presented and some theoretical calculations are detailed, aiming at an understanding of the discussion to explain the temperature dependence of acetaminophen adsorption onto different microporous activated carbons. See DOI: 10.1039/c4cp05273k
}

on the textural characteristics of the carbon, content and type of the surface functionalities, as well as on the structure of the organic molecules. Among the experimental parameters that influence the adsorption mechanism of organic molecules, $\mathrm{pH}$ is probably the most studied, since the net surface charge of the carbons and the adsorbate molecular structure are dependent on the solution $\mathrm{pH}^{6,9-24}$ Although less extensively, the influence of the water hardness, ${ }^{25}$ ionic strength, ${ }^{25}$ and temperature ${ }^{8-16,18,20,23,26}$ have also been evaluated.

According to thermodynamic principles, adsorption is an exothermic phenomenon; ${ }^{27}$ thus one could expect that an increase of temperature would always lead to a decrease of the adsorption capacity. However, in the literature there are a great number of studies reporting a positive effect of the temperature on the adsorption capacity in liquid, ${ }^{8-11,14,20,23,26}$ and also gas phase processes. ${ }^{28-30}$ In the particular case of liquid phase processes, the results obtained by Guedidi et al. ${ }^{9}$ on the adsorption of ibuprofen onto a granular activated carbon presenting both micro- and mesopores are illustrative of this unexpected behavior. The authors found that increasing the temperature by $30{ }^{\circ} \mathrm{C}$ promoted an increase of 34 percentage points on the monolayer capacity. In the study developed 